\title{
REACTION OF HYDROXYL RADICALS WITH TRICHLOROETHYLENE: EVIDENCE FOR CHLORINE ELIMINATION CHANNELS AT ELEVATED TEMPERATURES
}

\author{
LE ANN B. TICHENOR, ${ }^{1}$ ALEXEI J. LOZADA-RUIZ, ${ }^{1}$ TAKAHIM YAMADA, ${ }^{1}$ ABDULAZIZ EL-SINAWI, ${ }^{1}$ \\ PHILIP H. TAYLOR, ${ }^{1}$ JINGPING PENG ${ }^{2}$ XIAOHUA HU ${ }^{2}$ AND PAUL MARSHALL ${ }^{2}$ \\ ${ }^{1}$ Environmental Sciences and Engineering Group \\ University of Dayton Research Institute \\ 300 College Park \\ Dayton, OH 43469-0132, USA \\ ${ }^{2}$ Department of Chemistry \\ University of North Texas \\ P. O. Box 305070 \\ Denton, TX 76203-5070, USA
}

\begin{abstract}
Rate coefficients are reported for the gas-phase reaction of the hydroxyl radical $(\mathrm{OH})$ with $\mathrm{C}_{2} \mathrm{HCl}_{3}\left(k_{1}\right)$ over an extended temperature range at $740 \pm 10$ torr in a He bath gas. Rate measurements exhibited complex behavior with a slight negative temperature dependence at temperatures below $650 \mathrm{~K}$ and positive temperature dependence at higher temperatures $(650-750 \mathrm{~K})$. The three-parameter modified Arrhenius equation adequately describes all of the data and is given by (in units of $\mathrm{cm}^{3}$ molecule ${ }^{-1} \mathrm{~s}^{-1}$ )
\end{abstract}

$$
k_{1}(291-750 \mathrm{~K})=(3.76 \pm 0.36) \times 10^{-21} T^{2.76 \pm 0.18} \exp (1266.3 \pm 41.2) / T
$$

Error limits are $2 \sigma$ values. The activation energy derived from an Arrhenius fit to the data below $650 \mathrm{~K}$ is in good agreement with previous studies $(<0.6 \mathrm{kcal} / \mathrm{mol}$ deviation).

Quantum Rice-Ramsperger-Kassel (QRRK) modeling results are in reasonable agreement with experimental results and indicate the reaction is chemically activated. Although adduct stabilization and chlorine elimination channels are pressure dependent, the overall reaction is pressure independent above $0.1 \mathrm{~atm}$. At temperatures characteristic of postcombustion conditions (i.e., $\sim 1000 \mathrm{~K}$ ), Cl elimination is the dominant reaction. $\mathrm{H}$ abstraction was found to be significant only at very high temperatures. The lack of a measurable kinetic isotope effect for $k_{1}$ is consistent with the modeling results. Based on the new measurements reported here and with the assumption that $\mathrm{Cl}$ elimination accounts for the entire measured rate at $\sim 750$ $\mathrm{K}$, the extrapolated product-specific rate constant is given by (in units of $\mathrm{cm}^{3}$ molecule $\mathrm{s}^{-1}$ )

$$
k_{\mathrm{Cl}}(298-1500 \mathrm{~K})=(6.87 \pm 0.30) \times 10^{-10} T^{-0.50 \pm 0.04} \exp (-1530.5 \pm 42.4) / T
$$

Error limits are $2 \sigma$ values. This $\mathrm{Cl}$ elimination rate constant at $1000-1500 \mathrm{~K}$ is a factor of $5-8$ times larger than extrapolation of previous low-temperature measurements. At $2000 \mathrm{~K}, \mathrm{H}$ abstraction is a factor of 2-3 times faster than Cl elimination.

\section{Introduction}

Trichloroethylene $\left(\mathrm{C}_{2} \mathrm{HCl}_{3}\right)$ is a widely used chlorinated solvent with an annual global emission rate of 200,000 metric tons [1,2]. High-temperature incineration remains the best available technology for the complete and permanent disposal of this toxic compound. An important process contributing to the initial destruction of halogenated hydrocarbons is reaction with $\mathrm{OH}$ radicals $[3,4]$

Previous measurements of the reaction of $\mathrm{OH}$ with $\mathrm{C}_{2} \mathrm{HCl}_{3}$ are limited to low temperatures $(220$ to $459 \mathrm{~K}$ ) [5-8]. The reaction mechanism is presumed to be addition to the $\pi$ electrons associated with the $\mathrm{C}=\mathrm{C}$ double bond. Kirchner et al. [8] measured the kinetics and reaction products from $\mathrm{OH}$ reactions with $\mathrm{C}_{2} \mathrm{HCl}_{3}$ at low temperatures (300$459 \mathrm{~K}$ ) and pressures ( $\sim 1$ torr) using electron impact mass spectrometry. The observed product distributions were complex, with the dominant mass spectra signals interpreted in terms of a reaction mechanism involving $\mathrm{OH}$ addition and subsequent $\mathrm{Cl}$ elimination. Chang and Kaufman [7] measured $\mathrm{OH}$ decay rates at low temperatures $(234-420 \mathrm{~K})$ and pressures (1.1 and 6.2 torr) for $k_{1}$, using the discharge-resonance fluorescence technique. They reported that the rate coefficients were independent of pressure, thus inferring that the addition complex is rapidly 
thermalized by collisions with He buffer gas at pressures of $\sim 1$ torr or greater or that a decomposition pathway is available.

Given the lack of available data above $450 \mathrm{~K}$, knowledge of the reaction rate constants and reaction mechanisms over an extended temperature range is essential to accurately predict the flame and postflame combustion behavior of these compounds. Of specific interest is the relative importance of adduct stabilization, $\mathrm{Cl}$ elimination, and $\mathrm{H}$ abstraction. We present absolute rate coefficients for the reaction of OH with $\mathrm{C}_{2} \mathrm{HCl}_{3}$ (and $\mathrm{C}_{2} \mathrm{DCl}_{3}$ ) $\left(k_{1}\right)$ at atmospheric pressure over an extended temperature range:

$$
\mathrm{C}_{2} \mathrm{HCl}_{3}+\mathrm{OH} \rightarrow \text { products } \quad\left(k_{1}\right)
$$

Arrhenius parameters are derived from the data. A comparison of these measurements with prior measurements at lower temperatures and pressures is discussed. Ab initio calculations were performed to estimate thermodynamic properties, enthalpies of formation, entropies, and heat capacities. Quantum Rice Ramsperger Kassel (QRRK) calculations were performed to calculate energy-dependent rate constants, $k(E)$, using the above thermodynamic properties.

\section{Experimental Approach and Data Reduction}

The experimental procedures were similar to those used in previous studies of the reaction of $\mathrm{OH}$ radicals with halogenated hydrocarbons $[9,10]$. Experimental aspects unique to this study are described briefly in the following paragraphs.

To minimize substrate photolysis at wavelengths $<300 \mathrm{~nm}$, HONO was used as a hydroxyl radical source [11]. Parts per million concentrations of pure HONO (>99\%) were generated as described by Febo et al. [12] and Brust et al. [13] HONO dissociates primarily into $\mathrm{NO}$ and $\mathrm{OH}$ when exposed to near-UV radiation of $351 \mathrm{~nm}$. A competing dissociation channel, production of $\mathrm{NO}_{2}$ and $\mathrm{H}$ atoms, has been observed to be negligible under similar experimental conditions [14]. A XeF excimer laser (Lamba Physik Compex Model 102) was used as the photodissociation source. Initial $[\mathrm{OH}]_{0}$ ranged from $\sim 3-9 \times 10^{10}$ molecules $\mathrm{cm}^{-3}$ and was determined based on the measured excimer fluence $(9-18 \mathrm{~mJ}$ $\mathrm{cm}^{-2}$ ), the most recent published value of the absorption cross-section for HONO $\left(1.54 \times 10^{-19}\right.$ $\mathrm{cm}^{2} /$ molecule at $351 \mathrm{~nm}$ [13], a quantum yield of unity [15], and measured values of $\left[\mathrm{NO}_{2}\right]$ taken to represent [HONO] determined using ion chromatography $\left(\sim 1-3 \times 10^{13}\right.$ molecules $\left.\mathrm{cm}^{-3}\right)$.

Initial substrate concentrations in the reactor, based on measured flow rates, ranged from $\sim 3 \times$ $10^{13}$ to $\sim 1 \times 10^{15}$ molecules $\mathrm{cm}^{-3}$. The absence of adsorption on the injector probe (coated with boric acid) and reactor walls was verified using gas chromatography-mass spectrometry (GC-MS) analysis. All experiments were conducted at a total pressure of $740 \pm 10$ torr. Samples of $\mathrm{C}_{2} \mathrm{HCl}_{3}$ (99.9\% pure) were obtained from Aldrich. GC-MS analyses indicated that this purity was met or exceeded.

The rate of disappearance of the $\mathrm{OH}$ may be presented as

$$
-d[\mathrm{OH}] / d t=k\left[A_{0}\right][\mathrm{OH}]+k_{\mathrm{d}}[\mathrm{OH}]
$$

where $k$ is the bimolecular rate constant, $A_{0}$ is the substrate concentration, and $k_{\mathrm{d}}$ is the first-order rate for the reaction of $\mathrm{OH}$ with $\mathrm{HONO}$ and also includes diffusion out of the reaction volume. This relationship holds in the absence of any secondary reactions that may form or deplete OH. Solution of this equation yields $[\mathrm{OH}]=[\mathrm{OH}]_{0} \exp -\left(k^{\prime} t\right)$, where $k^{\prime}=k+k_{\mathrm{d}}$. For all experiments, reactive and diffusive $\mathrm{OH}$ radical decay profiles exhibited exponential behavior and were fitted by the nonlinear expression

$$
[\mathrm{OH}]=[\mathrm{OH}]_{0} \exp -\left(k^{\prime} t\right)+\gamma
$$

where $\gamma$ is the constant background signal level and $t$ is the time delay between the laser pulses. Because the organic concentration was much greater than the $[\mathrm{OH}]$, pseudo-first-order exponential $\mathrm{OH}$ decays were observed, and the individual temperature-dependent rate constants were determined by $k^{\prime}=$ $k$ [substrate $]+k_{\mathrm{d}}$, where the bimolecular rate constant, $k$, is the slope of the least squares fit of $k^{\prime}$ versus the [organic]. Numerical modeling indicated that the dominant source of $\mathrm{OH}$ decay in the absence of $\mathrm{C}_{2} \mathrm{HCl}_{3}$ was reaction with $\mathrm{HONO}\left(k_{298}=\right.$ $4.5 \times 10^{-12} \mathrm{~cm}^{3}$ molecule ${ }^{-1} \mathrm{~s}^{-1}$ ) [14]. Typical values of $k_{\mathrm{d}}$ decreased from $\sim 250 \mathrm{~s}^{-1}$ at low temperatures to $\sim 100 \mathrm{~s}^{-1}$ at elevated temperatures and were indicative of reduced $\mathrm{HONO}$ concentrations in the reactor at elevated temperatures. With the addition of $\mathrm{C}_{2} \mathrm{HCl}_{3}$, values of $k^{\prime}$ varied from $\sim 275$ to $\sim 1550 \mathrm{~s}^{-1}$.

\section{Results}

Rate data were obtained from ambient temperatures to $\sim 750 \mathrm{~K}$, under atmospheric pressure conditions. $\mathrm{OH}$ signals were obtained at higher temperatures using the HONO source; however, a rapid $\mathrm{OH}$ consumption channel occurring on the timescale of $1 \mathrm{~ms}$ prevented further measurements. This competing $\mathrm{OH}$ consumption pathway was observed only above $750 \mathrm{~K}$ with the addition of $\mathrm{C}_{2} \mathrm{HCl}_{3}$. Gasphase thermal decomposition of $\mathrm{C}_{2} \mathrm{HCl}_{3}$ has been shown to be negligible at these temperatures (gasphase residence times $\ll 1 \mathrm{~s}$ ) [16]. A surface-mediated decomposition process resulting in the production of chlorinated radicals is a plausible explanation for the rapid $\mathrm{OH}$ consumption observed. 


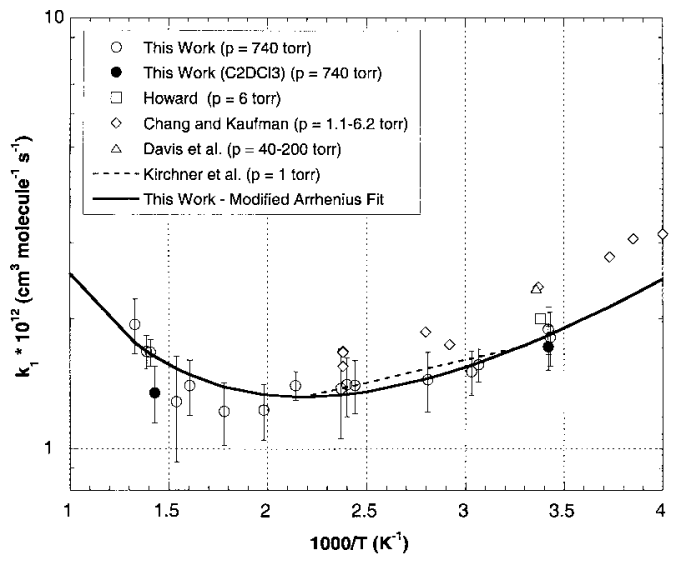

Fig. 1. Arrhenius plot of kinetic data for $k_{1}$. Error bars denote $\pm 2 \sigma$ random error limits. Also shown are the results of previous studies at lower temperatures and pressures and a three-parameter modified Arrhenius fit to the data $(p=740 \pm 10$ torr $)$.

All known absolute rate measurements for $k_{1}$ are summarized in Fig. 1 [1]. (Note: Our previous measurements for trichloroethylene [17] using $193 \mathrm{~nm}$ radiation to generate $\mathrm{OH}$ radicals are believed to be in error due to substrate photolysis and are not included in Fig. 1.) This work extends experimental measurement beyond the limit of $\sim 450 \mathrm{~K}$ reported previously. A variety of techniques were used in collecting these data. Examination of Fig. 1 shows agreement at room temperature, within combined experimental uncertainties, between our work and that reported previously [5-8].

Rate measurements for $k_{1}$ exhibited complex behavior with a slight negative temperature dependence at temperatures below $650 \mathrm{~K}$ and positive temperature dependence at higher temperatures. The three-parameter modified Arrhenius equation, calculated using a weighted, nonlinear least squares Levenberg-Marquardt algorithm, adequately describes all of the data and is given by (in units of $\mathrm{cm}^{3}$ molecule ${ }^{-1} \mathrm{~s}^{-1}$ )

$$
\begin{aligned}
& k_{1}(291-750 \mathrm{~K})=(3.76 \pm 0.36) \\
& \quad \times 10^{-21} T^{2.76 \pm 0.18} \exp (1266.3 \pm 41.2) / T
\end{aligned}
$$

Error limits are $2 \sigma$ values. The activation energy derived from an Arrhenius fit to the data below $650 \mathrm{~K}$ is also in good agreement with previous studies $(<0.6 \mathrm{kcal} / \mathrm{mol}$ deviation). The agreement between our rate measurements at 740 torr and prior measurements obtained between $\sim 1$ and 200 torr provides further verification that the reaction is in the high-pressure limit at temperatures below $1000 \mathrm{~K}$.

Rate coefficient measurements were also obtained with deuterated $\mathrm{C}_{2} \mathrm{HCl}_{3}$ to provide further insight into the reaction mechanism. Rate coefficient measurements with $\mathrm{C}_{2} \mathrm{DCl}_{3}$ at 292 and $699 \mathrm{~K}$ indicate the absence of a measurable isotope effect. This result indicates that $\mathrm{C}-\mathrm{H}$ bond breaking is not rate determining and infers that an $\mathrm{OH}$ addition mechanism dominates the measured $\mathrm{OH}$ decay rates throughout the temperature range of investigation.

\section{Theoretical Approach}

The composite $a b$ initio calculation method, G3(MP2) [18], and density functional theory (DFT) B3LYP/6-311 + G(3df,2p)//B3LYP/6-31G(d) were used to calculate thermodynamic properties of reactants, intermediate radicals, transition states (TSs), and products with the Gaussian94 [19] and Gaussian98 [20] computer codes. G3(MP2) uses HF/6$31 G(d)$ level of theory to calculate frequencies and zero point energies (ZPEs), followed by MP2(full)/ 6-31G(d)level of theory to determine the final geometries. G3(MP2), then, uses QCISD(T)/6-31G(d) and MP2(fc)/G3MP2large for the higher-energy correction [18]. The enthalpies of formation of the reactants were obtained from the literature [21,22]. The enthalpies of formation at $298 \mathrm{~K}$ for intermediates and products were determined by the energy differences from the reactants, calculated by G3(MP2) [18]. ZPE and thermal correction to 298 $\mathrm{K}$ were incorporated to estimate enthalpies of formation [23]. The activation energies, except for the addition entrance channel $\left(\mathrm{C} \cdot \mathrm{Cl}_{2} \mathrm{CHCl}-\mathrm{OH}\right.$ and $\mathrm{C} \cdot \mathrm{HClCCl}_{2}-\mathrm{OH}$ ), were determined by the relative energy differences between each respective intermediate and TS whose energies were calculated by B3LYP/6-311 + G(3df,2p)//B3LYP/6-31G(d) level of theory. QCISD $(\mathrm{T}) / 6-31 \mathrm{G}(\mathrm{d})$ calculation, which is one of G3(MP2) calculation steps, was not successful for several TSs, and necessitated the use of DFT. Entropy and heat capacity were calculated based on calculated moments of inertia and frequencies using statistical mechanics.

For the reactions where thermodynamic properties of transition states were calculated by ab initio methods, $k$ values were fitted by three parameters, $B, n$, and $C$, over a temperature range of 200 to 2000 $\mathrm{K}$, as expressed by

$$
k=B(T)^{n} \exp (-C / R T)
$$

High-pressure limit $A$ factors of unimolecular reactions were calculated using transition-state theory (TST) [24] along with $a b$ initio data for the determination of the structure, and vibrational and rotational contributions to the entropies of the TSs. Loss (or gain) of internal rotors and change of optical isomer and symmetry numbers were also incorporated into the calculation of entropy for each TS. Entropies of reactants and TSs were then used to determine the pre-exponential factor, $A$, via classical TST for a unimolecular reaction 


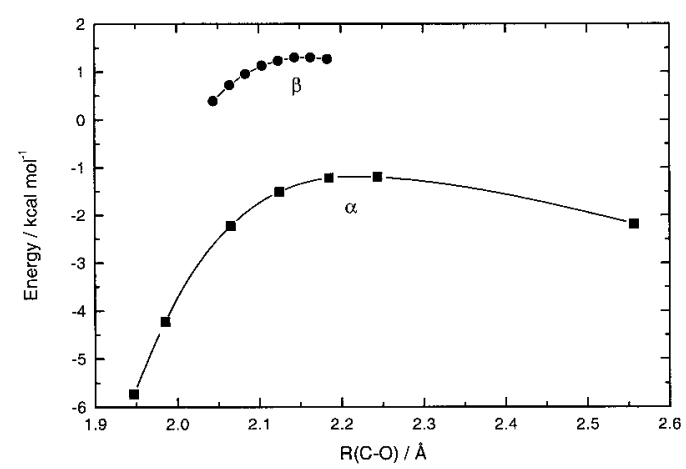

FIG. 2. Classical energies (no ZPE) relative to $\mathrm{OH}+$ $\mathrm{C}_{2} \mathrm{HCl}_{3}$ for addition of $\mathrm{OH}$ at the $\mathrm{CHCl}$ end ( $\alpha$, squares) and the $\mathrm{CCl}_{2}$ end ( $\beta$, circles), calculated at the PMP4/6$311+\mathrm{G}(\mathrm{d}, \mathrm{p}) / \mathrm{HF} 6-31(\mathrm{~d}, \mathrm{p})$ level of theory.

$$
A=\left(k_{\mathrm{b}} T / h\right) \exp \left(\Delta S^{*} / R\right)
$$

where $h$ is Planck's constant, $k_{\mathrm{b}}$ is the Boltzmann constant, and $\Delta S^{\neq}$is equal to $S_{298, \mathrm{Ts}}^{\circ}-S_{298 \text {,reactant }}^{\circ}$. A QRRK analysis [25-28] for $k(E)$, combined with the modified $\beta$ collision analysis of Gilbert et al. [29] or fall-off, was used to predict pressure-dependent rate constants.

Variational transition-state theory (VTST) calculations were performed to estimate the rate of $\mathrm{OH}$ addition to $\mathrm{C}_{2} \mathrm{HCl}_{3}$. The calculations were carried out as follows. First, the reaction coordinates for addition of $\mathrm{OH}$ to each end of the $\mathrm{C}=\mathrm{C}$ bond were defined as intrinsic reaction coordinates (IRCs) at the HF/6-31G(d,p) level. For each IRC, the geometry of the system was optimized at various fixed C$\mathrm{O}$ separations, and frequencies were obtained normal to the IRC, also at the HF/6-31G(d,p) level of theory. The results were scaled by a factor of 0.90 .
Then, energies were computed at the spin-projected PMP4/6-311 + G(d,p) level, relative to reactants [19]. These energies, geometries, and frequencies were used to derive canonical TST rate constants as a function of position along the IRC. At each temperature, the VTST result was obtained by interpolation to find the minimum rate constant.

These VTST results correspond to the high-pressure limit for $\mathrm{OH}$ addition, where the initially formed excited adduct is always stabilized by collisions. At finite pressures, some fraction of the excited adducts can dissociate back to $\mathrm{OH}+\mathrm{C}_{2} \mathrm{HCl}_{3}$ before collisional stabilization or fragmentation, and thus the observed rate constant is likely to be smaller than the calculated one. At a given pressure, this effect will become more pronounced at elevated temperatures, because the reaction moves further from the high-pressure limit.

The variationally located transition states lie at CO separations approximately $0.05 \AA$ smaller than the local maxima along the IRCs. As seen in Fig. 2, the barrier for $\alpha$ addition lies approximately $1 \mathrm{kcal} / \mathrm{mol}$ below the reactants' energy, whereas $\beta$ addition requires overcoming a positive barrier of around +1 $\mathrm{kcal} / \mathrm{mol}$. The $\beta$ addition channel is also found to be somewhat less favorable in an entropy context as well (the pre-exponential factor is approximately 8 times smaller, see Tables 1 and 2). The derived VTST rate constants are plotted in Fig. 3. The $\beta$ channel has a simple positive temperature dependence. The $\alpha$ channel is more important at all temperatures and has a more complex behavior. The negative relative transition state energy implies a negative temperature dependence for the rate constant, an effect which dominates at low temperatures, however, increases in temperature more rapidly increase the partition function of the loose TS as compared to

TABLE 1

Input QRRK parameters, high-pressure limit rate constants for $\alpha$ addition of $\mathrm{OH}$ to $\mathrm{C}_{2} \mathrm{Cl}_{3} \mathrm{H}$

\begin{tabular}{|c|c|c|c|}
\hline Reaction & $B\left(\mathrm{~s}^{-1}\right.$ or $\mathrm{cm}^{3} /($ molecule $\left.\mathrm{s})\right)$ & $n$ & $C(\mathrm{kcal} / \mathrm{mol})$ \\
\hline $1 \mathrm{C}_{2} \mathrm{Cl}_{3} \mathrm{H}+\mathrm{OH} \Rightarrow \mathrm{C} \cdot \mathrm{Cl}_{2} \mathrm{CClHOH}$ & $1.98 \mathrm{E}-19$ & 2.40 & -1.49 \\
\hline$-1 \mathrm{C} \cdot \mathrm{Cl}_{2} \mathrm{CClHOH} \Rightarrow \mathrm{C}_{2} \mathrm{Cl}_{3} \mathrm{H}+\mathrm{OH}$ & $6.20 \mathrm{E}+06$ & 2.40 & 36.14 \\
\hline $2 \mathrm{C} \cdot \mathrm{Cl}_{2} \mathrm{CClHOH} \Rightarrow \mathrm{C}_{2} \mathrm{Cl}_{3} \mathrm{OH}+\mathrm{H}$ & $4.28 \mathrm{E}+07$ & 2.21 & 47.12 \\
\hline $3 \mathrm{C} \cdot \mathrm{Cl}_{2} \mathrm{CClHOH} \Rightarrow \mathrm{CCl}_{2} \mathrm{CHOH}+\mathrm{Cl}$ & $1.69 \mathrm{E}+13$ & 0.00 & 24.74 \\
\hline $4 \mathrm{C} \cdot \mathrm{Cl}_{2} \mathrm{CClHOH} \Rightarrow \mathrm{CCl}_{2} \mathrm{HCClHO}$ & $7.10 \mathrm{E}+08$ & 0.72 & 41.18 \\
\hline$-4 \mathrm{CCl}_{2} \mathrm{HCClHO} \cdot \Rightarrow \mathrm{C} \cdot \mathrm{Cl}_{2} \mathrm{CClHOH}$ & $3.63 \mathrm{E}+09$ & 0.41 & 26.77 \\
\hline $5 \mathrm{C} \cdot \mathrm{Cl}_{2} \mathrm{CClHOH} \Rightarrow \mathrm{CCl}_{3} \mathrm{C} \cdot \mathrm{HOH}$ & $1.23 \mathrm{E}+10$ & 1.10 & 12.41 \\
\hline$-5 \mathrm{CCl}_{3} \mathrm{C} \cdot \mathrm{HOH} \Rightarrow \mathrm{C} \cdot \mathrm{Cl}_{2} \mathrm{CClHOH}$ & $9.63 \mathrm{E}+10$ & 0.76 & 2.98 \\
\hline $6 \mathrm{CCl}_{3} \mathrm{C} \cdot \mathrm{HOH} \Rightarrow \mathrm{CCl}_{2} \mathrm{CHOH}+\mathrm{Cl}$ & $1.69 \mathrm{E}+13$ & 0.00 & 15.86 \\
\hline $7 \mathrm{C}_{2} \mathrm{Cl}_{3} \mathrm{H}+\mathrm{OH} \Rightarrow \mathrm{C} \cdot \mathrm{ClCCl}_{2}+\mathrm{H}_{2} \mathrm{O}$ & $2.67 \mathrm{E}-16$ & 1.30 & 7.45 \\
\hline
\end{tabular}

Note: Grouped geometric mean frequencies of the adduct with effective degeneracies: $100.0 \mathrm{~cm}^{-1}(5.304), 757.5 \mathrm{~cm}^{-1}$ (8.050), $1980.8 \mathrm{~cm}^{-1}$ (3.646). Lennard-Jones parameters: $\mathrm{C}_{2} \mathrm{Cl}_{3} \mathrm{HOH}$ adduct: $\sigma=5.327 \AA$, $\varepsilon / k_{\mathrm{B}}=469.4 \mathrm{~K}$; He bath gas: $\sigma=2.576 \AA, \varepsilon / k_{\mathrm{B}}=470.0 \mathrm{~K}$. 
TABLE 2

Input QRRK parameters, high-pressure limit rate constants for $\beta$ addition of $\mathrm{OH}$ to $\mathrm{C}_{2} \mathrm{Cl}_{3} \mathrm{H}$

\begin{tabular}{|c|c|c|c|}
\hline Reaction & $B\left(\mathrm{~s}^{-1}\right.$ or $\mathrm{cm}^{3} /($ molecule-s $\left.)\right)$ & $n$ & $C(\mathrm{kcal} / \mathrm{mol})$ \\
\hline $1 \mathrm{C}_{2} \mathrm{Cl}_{3} \mathrm{H}+\mathrm{OH} \Rightarrow \mathrm{C} \cdot \mathrm{ClHCCl}_{2} \mathrm{OH}$ & $4.32 \mathrm{E}-20$ & 2.43 & 1.43 \\
\hline$-1 \mathrm{C} \cdot \mathrm{ClHCCl}_{2} \mathrm{OH} \Rightarrow \mathrm{C}_{2} \mathrm{Cl}_{3} \mathrm{H}+\mathrm{OH}$ & $1.90 \mathrm{E}+05$ & 2.43 & 38.33 \\
\hline $2 \mathrm{C} \cdot \mathrm{ClHCCl}_{2} \mathrm{OH} \Rightarrow \mathrm{CClHCClOH}+\mathrm{Cl}$ & $1.69 \mathrm{E}+13$ & 0.00 & 27.41 \\
\hline $3 \mathrm{C} \cdot \mathrm{ClHCCl}_{2} \mathrm{OH} \Rightarrow \mathrm{CClH}_{2} \mathrm{CCl}_{2} \mathrm{O}$ & $2.42 \mathrm{E}+09$ & 0.52 & 37.37 \\
\hline$-3 \mathrm{CClH}_{2} \mathrm{CCl}_{2} \mathrm{O} \cdot \Rightarrow \mathrm{C} \cdot \mathrm{ClHCCl}_{2} \mathrm{OH}$ & $1.18 \mathrm{E}+10$ & 0.39 & 25.13 \\
\hline $4 \mathrm{C} \cdot \mathrm{ClHCCl}_{2} \mathrm{OH} \Rightarrow \mathrm{CHCl}_{2} \mathrm{C} \cdot \mathrm{ClOH}$ & $3.73 \mathrm{E}+13$ & -0.86 & 6.45 \\
\hline$-4 \mathrm{CHCl}_{2} \mathrm{C} \cdot \mathrm{ClOH} \Rightarrow \mathrm{C} \cdot \mathrm{ClHCCl}_{2} \mathrm{OH}$ & $1.04 \mathrm{E}+13$ & -0.55 & 7.53 \\
\hline $5 \mathrm{CHCl}_{2} \mathrm{C} \cdot \mathrm{ClOH} \Rightarrow \mathrm{CClHCClOH}+\mathrm{Cl}$ & $1.69 \mathrm{E}+13$ & 0.00 & 28.58 \\
\hline $6 \mathrm{CHCl}_{2} \mathrm{C} \cdot \mathrm{ClOH} \Rightarrow \mathrm{C}_{2} \mathrm{Cl}_{3} \mathrm{OH}+\mathrm{H}$ & $1.31 \mathrm{E}+09$ & 1.62 & 46.55 \\
\hline
\end{tabular}

Note: Grouped geometric mean frequencies of the adduct with effective degeneracies: $623.0 \mathrm{~cm}^{-1}(8.425), 596.8 \mathrm{~cm}^{-1}$ (6.341), $2225.0 \mathrm{~cm}^{-1}$ (2.734). Lennard-Jones parameters: $\mathrm{C}_{2} \mathrm{Cl}_{3} \mathrm{HOH}$ adduct: $\sigma=5.327 \AA$, $\varepsilon / k_{\mathrm{B}}=469.4 \mathrm{~K}$; He bath gas: $\sigma=2.576 \AA, \varepsilon / k_{\mathrm{B}}=470.0 \mathrm{~K}$.

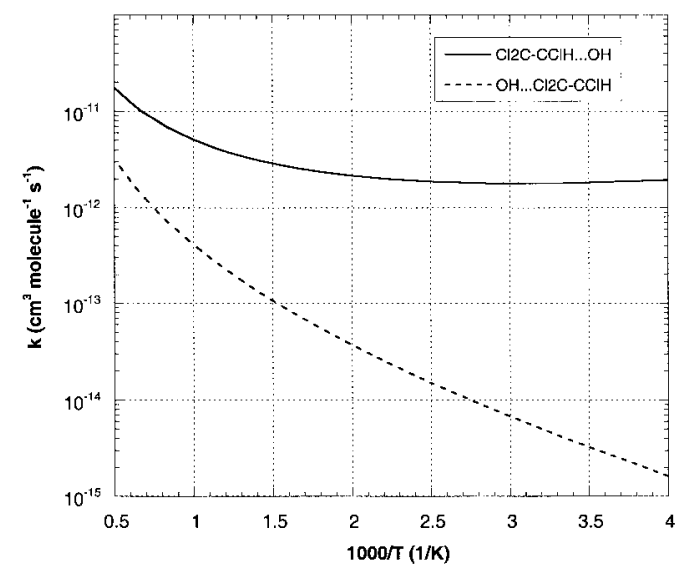

FIG. 3. Variational transition state theory rate constants for $\mathrm{OH}$ addition to $\mathrm{C}_{2} \mathrm{HCl}_{3}$. Addition of $\mathrm{OH}$ to both carbon sites is shown. The $\mathrm{OH}$ rotation was treated as a hindered rotor with a barrier of $2.4 \mathrm{kcal} / \mathrm{mol}$.

the reactants, leading to a positive activation energy at higher temperatures.

\section{Modeling Results}

Tables 1 and 2 present the high-pressure-limit Arrhenius parameters for the various pathways for $\alpha$ and $\beta \mathrm{OH}$ addition reactions, respectively. Figs. 4 and 5 present a comparison of the modified Arrhenius fit of the experimental data (extrapolated to $2000 \mathrm{~K}$ ) with the QRRK-predicted expression. The fit between the two expressions is within $10 \%$ at the extremes of the temperature range (285 and 2000 $\mathrm{K})$ and within a factor of $\sim 2$ at intermediate temperatures. Overall, given the lack of adjusted parameters, the agreement is quite remarkable, though

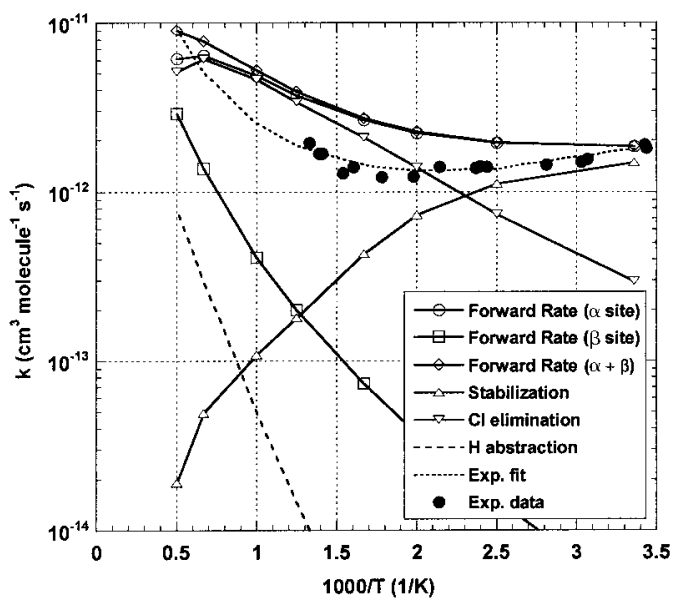

FIG. 4. Arrhenius plot of the QRKK model results $(p=$ $1 \mathrm{~atm})$. Shown are the predicted forward rate for the $\alpha$ and $\beta$ sites. Also shown are the stabilization ( $\alpha$ site only) and chlorine elimination channel and the $\mathrm{H}$-atom abstraction channel. The experimental data and a best fit extrapolated to $2000 \mathrm{~K}$ have also been included.

QRRK modeling consistently predicts larger values throughout the temperature range, with slightly positive temperature dependence. This contrasts with the slight negative temperature dependence of the experimental data below $600 \mathrm{~K}$. (The stabilized adduct $\left(\mathrm{C} \cdot \mathrm{Cl}_{2} \mathrm{CClHOH}\right)$ is the only path that shows a negative temperature dependence, and though it is a substantial dependence, it has a markedly smaller relative rate.)

Figure 4 also shows the QRRK-estimated temperature-dependent reaction rate constants for the various path products. The predicted dominant product is 1,1-dichloroethenol, formed by $\mathrm{OH}$ addition to the $\alpha$ site, followed by $\mathrm{Cl}$ elimination from 


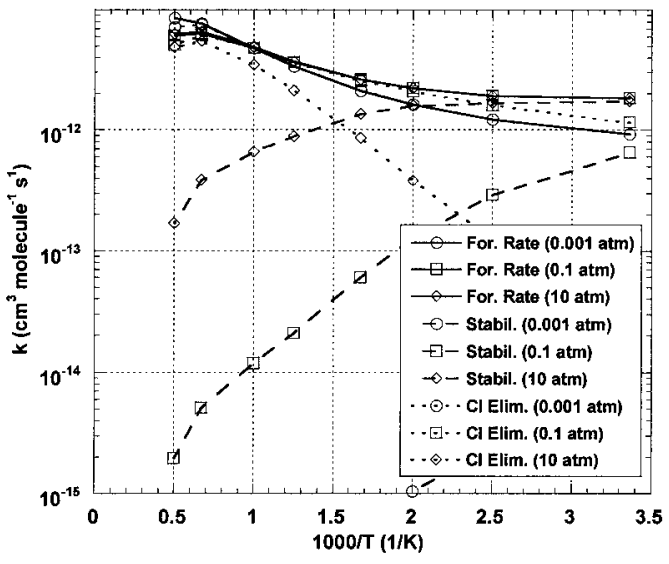

FIG. 5. QRRK-determined forward rate constants as a function of pressure and temperature. Included are the forward rate constant and the selected, individual rate constants at pressures of $0.001,0.1$, and $10.0 \mathrm{~atm}$ ( $\alpha$ site only).

POTENTLAL ENERGY DIAGRAM $\mathrm{CCl} 2=\sqrt{\mathrm{CClH}}+\mathrm{OH}$

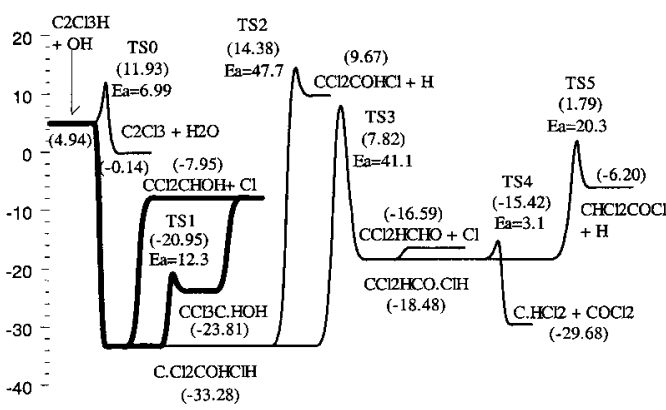

FIG. 6. Potential energy diagrams for the $\mathrm{OH}$ addition to $\mathrm{C}_{2} \mathrm{HCl}_{3}\left(\alpha\right.$ site). Energies are $\Delta H_{\mathrm{f} 298}^{\circ}$ in $\mathrm{kcal} / \mathrm{mol}$. Thick lines represent energetically favorable pathways.

the stabilized adduct $\left(\mathrm{C} \cdot \mathrm{Cl}_{2} \mathrm{COHClH}\right.$, see Fig. 6). The second dominant product is 1,2-dichloroethenol, which is formed by $\mathrm{OH}$ addition to the $\beta$ site, followed by isomerization and $\mathrm{Cl}$ elimination (intermediate radicals are $\mathrm{C} \cdot \mathrm{HClCOHCl}_{2}$ and $\mathrm{CHCl}_{2} \mathrm{C} \cdot \mathrm{OHCl}$, see Fig. 7 ). The temperature dependence of these two separate paths is shown in Fig. 4. At temperatures characteristic of flame conditions $(2000 \mathrm{~K}), \mathrm{H}$-atom abstraction is two times faster than $\mathrm{Cl}$ elimination. The formation of $\mathrm{C}_{2} \mathrm{Cl}_{3} \mathrm{OH}$ by $\mathrm{H}$ displacement is insignificant, even under flame conditions.

These results compare favorably with those previously reported by Kirchner et al. [8], who found by mass spectrometry that the dominant products were likely formed by $\mathrm{Cl}$ elimination processes.

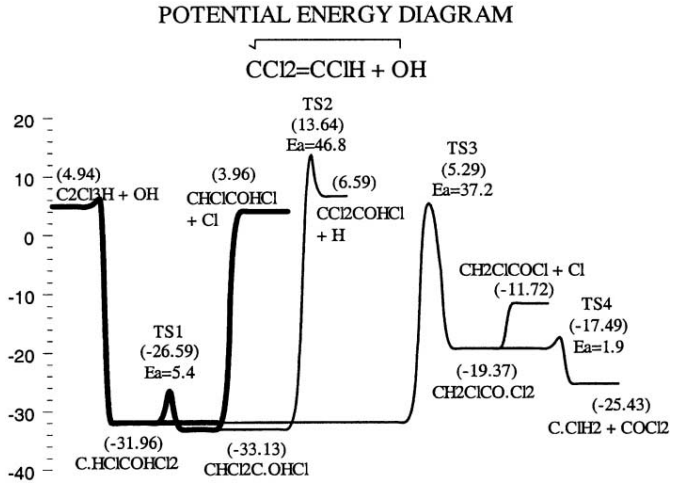

FIG. 7. Potential energy diagrams for the $\mathrm{OH}$ addition to $\mathrm{C}_{2} \mathrm{HCl}_{3}\left(\beta\right.$ site). Energies are $\Delta H_{\mathrm{f} 298}^{\circ}$ in $\mathrm{kcal} / \mathrm{mol}$. Thick lines represent energetically favorable pathways.

Chang and Kaufman [7] reported that the reaction was not pressure dependent under their experimental conditions (1.1-6.2 torr, 234-420 K). This is consistent with the modeling results. As seen in Fig. 5, the overall forward reaction is not a function of pressure above $0.1 \mathrm{~atm}$. Cl elimination and the formation of the initial stabilized adduct does show the expected pressure dependence. Under the conditions of the previous experiments $(\sim 0.001 \mathrm{~atm})$, Cl elimination is the only reaction channel that is important, that is, all adducts eliminate $\mathrm{Cl}$ atoms. The formation of 1,1-dichloroethenol has recently been observed as a significant product in flame studies of $\mathrm{C}_{2} \mathrm{HCl}_{3}$ combustion under low $\mathrm{Cl} / \mathrm{H}$ ratio conditions [30]. A mechanism involving $\mathrm{OH}$ addition to $\mathrm{C}_{2} \mathrm{HCl}_{3}$ followed by $\mathrm{Cl}$ elimination was proposed to account for the formation of 1,1-dichloroethenol. This study supports the proposed pathway.

\section{Summary}

New, atmospheric pressure, absolute rate measurements are presented for the reaction of $\mathrm{OH}$ radicals with $\mathrm{C}_{2} \mathrm{HCl}_{3}$. In contrast to previous studies at lower temperatures, where a slight negative temperature dependence was observed, the new measurements at higher temperatures and pressures indicated more complex behavior with a slight negative temperature dependence at temperatures below $650 \mathrm{~K}$ and a positive temperature dependence at higher temperatures $(650-750 \mathrm{~K})$.

Theoretical calculations indicate that this reaction involves a chemically activated system. The lack of any observed pressure dependence in previous lowtemperature studies is consistent with this analysis. At room temperature, the dominant reaction channel is adduct stabilization. Our calculations indicate that adduct stabilization accounts for $\sim 85 \%$ of the 
overall reaction at $1 \mathrm{~atm}$ and $298 \mathrm{~K}$. At higher temperatures encompassing postcombustion conditions $(1000 \mathrm{~K}), \mathrm{Cl}$ elimination yielding 1,1-dichloroethenol is the dominant reaction. The lack of a measurable kinetic isotope effect under these conditions is consistent with this analysis. At even higher temperatures that encompass flame conditions (2000 K), $\mathrm{H}$ abstraction is the dominant pathway, and ab initio calculations suggest a rate factor of 2 greater that $\mathrm{Cl}$ elimination. Based on the new measurements reported here and with the assumption that $\mathrm{Cl}$ elimination accounts for the entire measured rate at $\sim 750$ $\mathrm{K}$, the extrapolated product-specific rate constant is given by (in units of $\mathrm{cm}^{3}$ molecule $\mathrm{e}^{-1} \mathrm{~s}^{-1}$ )

$$
\begin{aligned}
& k_{\mathrm{Cl}}(298-1500)=(6.87 \pm 0.30) \\
& \quad \times 10^{-10} T^{-0.50 \pm 0.04} \exp (-1530.5 \pm 42.4) / T
\end{aligned}
$$

Error limits are $2 \sigma$ values. This $\mathrm{Cl}$ elimination rate coefficient at $1000-1500 \mathrm{~K}$ is a factor of 5-8 times larger than extrapolation of previous low-temperature measurements [5-8].

In previously completed studies of $\mathrm{OH}+\mathrm{C}_{2} \mathrm{Cl}_{4}$, the room temperature rate constant and the observed positive temperature dependence of the rate measurements was consistent with the location of a transition state for $\mathrm{OH}$ addition to the $\pi$ electron system that lies higher in energy than that of the reactants [11]. This is in contrast to $\mathrm{OH}$ addition to $\mathrm{C}_{2} \mathrm{HCl}_{3}$ where the energy of the transition state (for $\mathrm{OH}$ addition to the $\alpha$ site, the dominant reaction channel) is below the energy of the reactants. The order of magnitude increase in room temperature rate constant for $\mathrm{C}_{2} \mathrm{HCl}_{3}$ versus $\mathrm{C}_{2} \mathrm{Cl}_{4}$ is due, in part, to the relative energies of the initial transition state. Future efforts will attempt to verify the predicted products and measure the branching ratios to confirm these mechanisms.

\section{Acknowledgments}

The authors acknowledge support from the Environmental Protection Agency (grant R82-6169-01-0). The authors would also like to thank Dr. J. W. Bozzelli for his comments during the $a b$ initio calculations.

\section{REFERENCES}

1. McCulloch, A., and Midgley, P. M., Atmos. Environ. 30:601 (1996).

2. McCulloch, A., Aucott, M. L., Graedel, T. E., Kleiman, G., Midgley, P. M., and Li, Y.-F., J. Geophys. Res. 104:8417 (1999).

3. Fairchild, P. W., Smith, G. P., and Crosley, D. R., Pres. Combust. Inst. 19:107 (1982).

4. Warnatz, J., Bockhorn, H., Moser, A., and Wenz, H. W., Proc. Combust. Inst. 19:197 (1982).
5. Howard, C. J., J. Chem. Phys. 65:4771 (1976).

6. Davis, D., Machado, U., Smith G., Wagner, S., and Watson, R. T., unpublished data cited in Watson, R. T., J. Phys. Chem. Ref. Data 6:871 (1977).

7. Chang, J. S., and Kaufman, F., J. Chem. Phys. 66:4989 (1977).

8. Kirchner, K., Helf, D., Ott, P., and Vogt, S., Ber. Bunsen-Ges. Phys. Chem. 94:77 (1990).

9. Fang, T. D., Taylor, P. H., Dellinger, B., Ehlers, C. J., and Berry, R. J., J. Phys. Chem. 101:5758 (1997).

10. Fang, T. D., Taylor, P. H., and Berry, R. J., J. Phys. Chem. A 103:2700 (1999).

11. Tichenor, L. B., Taylor, P. H., Yamada, T., Peng, J., Hu, X., and Marshall, P., J. Phys. Chem. A 104:1700 (2000).

12. Febo, A., Perrino, C., Gherardi, M., and Sparapani, R., Environ. Sci. Technol. 29:2390 (1995).

13. Brust, A. S., Becker, K. H., Kleffmann, J., and Wiesen, P., Atmos. Environ. 34:13 (2000).

14. Wollenhaupt, M., Carl, S. A., Horowitz, A., and Crowley, J. N., J. Phys. Chem. 104:2695 (2000).

15. Cox, R. A., J. Photochem. 3:175 (1974).

16. Taylor, P. H., Tirey, D. A., Rubey, W. A., and Dellinger, B., Combust. Sci. Technol. 101:75 (1994).

17. Jiang, Z., Taylor, P. H., and Dellinger, B., J. Phys. Chem. 97:5050 (1993).

18. Curtiss, L. A., and Redfern, P. C., J. Chem. Phys. 110:4703 (1999).

19. Frisch, M. J., Trucks, G. W., Schlegel, H. B., Gill, P. M. W., Johnson, B. G., Robb, M. A., Cheeseman, R. J., Keith, T., Petersson, G. A., Montgomery, J. A., Raghavachari, K., Al-Laham, M. A., Zakrzewski, V. G., Ortiz, J. V., Foresman, J. B., Cioslowski, J., Stefanov, B. B., Nanayakkara, A., Challacombe, M., Peng, C. Y., Ayala, P. Y., Chen, W., Wong, M. W., Andres, J. L., Replogle, E. S., Gomperts, R., Martin, R. L., Fox, D. J., Binkley, J. S., Defrees, D. J., Baker, J., Stewart, J. P., Head-Gordon, M., Gonzalez, C., and Pople, J. A., Gaussian94, Gaussian, Inc., Pittsburgh, PA, 1995.

20. Frisch, M. J., Trucks, G. W., Schlegel, H. B., Scuseria, G. E., Robb, M. A., Cheeseman, J. R., Zakrzewski, V. G., Montgomery, J. A., Stratmann, R. E., Burant, J. C., Dapprich, J. M., Millan, J. M., Daniels, A. D., Kudin, K. N., Strain, M. C., Farcas, O., Tomasi, J., Barone, V., Cossi, M., Cammi, R., Mennucci, B., Pomelli, C., Adamo, C., Clifford, S., Ochterski, J., Petersson, G. A., Ayala, P. Y., Cui, Q., Morokuma, K., Marick, D. K., Rabuck, A. D., Raghavachari, K., Foresman, J. B., Cioslowski, J., Ortiz, J. V., Stefanov, B. B., Liu, G., Liashenko, A., Piskorz, P., Komaromi, I., Gomperts, R., Martin, R. L., Fox, D. J., Keith, T., AlLaham, M. A., Peng, C. Y., Nanayakkara, A., Gonzalez, C., Challacombe, M., Gill, P. M. W., Johnson, B., Chen, W., Replogle, E. S., and Pople, J. A., Gaussian98, Gaussian, Inc., Pittsburgh, PA, 1998.

21. Papina, T. S., and Kolesov, V. P., Russ. J. Phys. Chem. 59:1289 (1985). 
22. Stull, D. R., and Prophet, H., JANAF Thermochemical Tables, NSRDS-NBS 37, U.S. Government Printing Office, Washington DC, 1971.

23. Hehre, W. J., Radom, L., Schleyer, P. R., and Pople, J. A., Ab Initio Molecular Orbital Theory, John Wiley \& Sons, New York, 1986.

24. Benson, S. W., Thermochemical Kinetics, Wiley-Interscience, New York, 1976.

25. Westmoreland, P. R., Combust. Sci. Technol. 82:1515 (1992).
26. Bozzelli, J. W., Dean, A. M., and Ritter, E. R., Combust. Sci. Technol. 80:169 (1991).

27. Dean, A. M., J. Phys. Chem. 89:4500 (1985).

28. Chang, A. M., Bozzelli, J. W., and Dean, A. M., Zeitschrift fur Phys. Chemie, in press, 2000.

29. Gilbert, R. G., Luther, K., and Troe, J., Ber. BunsenGes. Phys. Chem. 87:169 (1983).

30. Werner, J. H., and Cool, T. A., Combust. Flame 120:125 (1999). 